\title{
Carcinoma with multiple ectopic hormone secretion and associated myopathy
}

\author{
DeREK R. Cullen* \\ M.B.Durh., M.R.C.P., M.R.C.P.(Glasg.) \\ Registrar in Medicine
}

\author{
BERNARD E. TOMLINSON \\ M.D., F.R.C.P.
}

Consultant Pathologist

Newcastle General Hospital, Newcastle upon Tyne

IN RECENT years, many cases of neoplasms in non-endocrine tissues associated with endocrine disturbances have been recorded and there is much evidence to suggest that these are due to secretion by the tumours of substances with hormonal activity. The tumours involved vary in origin but the commonest is a bronchogenic carcinoma.

Cushing's syndrome was the first of these endocrine manifestations to be reported (Brown, 1928) and is due to the tumour secreting an adrenocorticotrophic-like substance (Meador et al., 1962). Since then, bronchogenic carcinomas have been shown to secrete antidiuretic hormone (Schwartz et al., 1957; Ross, 1963); a parathormone-like substance (Tashjian, Levine \& Munson, 1964); 5-hydroxytryptamine (Williams \& Azzopardi, 1960), and thyroid-stimulating hormone (de Gennes, Bricaire \& Leprat, 1962). Gynaecomastia has also been recorded in males with lung tumours (Hardy, 1960) and recently gonadotrophins have been isolated from the lung-tumour tissue (Fusco \& Rosen, 1966).

Very rarely neoplasms may secrete more than one ectopic hormone, and it is the purpose of this paper to report such a case together with the occurrence of a myopathy, probably the result of endogenous steroid production. This latter occurrence has not previously been described in these circumstances to our knowledge.

\section{Case report}

A man, aged 59 years, presented as an emergency with a month's history of upper back pain. This was intermittent, each attack lasting several hours. For 3 months he had experienced

\footnotetext{
*At present: Registrar in Medicine, The Royal Infirmary, Edinburgh.
}

progressive lassitude with loss of appetite and considerable loss of weight. His admission was precipitated when he had a major epileptic fit which re-occurred on two occasions shortly after entering hospital.

On examination, he looked ill and emaciated. His skin was pigmented and he also had buccal pigmentation. There was a well-marked dorsal kyphoscoliosis and slight sacral oedema. He was afebrile, BP $120 / 60 \mathrm{~mm} \mathrm{Hg}$. There was no clinical abnormality in the chest, cardiovascular system or central nervous system. The liver was enlarged to three fingers below the costal margin but there was no other abnormality in the abdomen.

Investigations: $\quad \mathrm{Hb} 12.5 \mathrm{~g} / 100 \mathrm{ml}$; WBC $12,400 / \mathrm{mm}^{3}$; PCV $40 \%$; ESR $10 \mathrm{~mm} / \mathrm{hr}$ (Westergren). A chest X-ray showed some prominence of the left hilar shadow with elevation of the left hemi-diaphragm. The lateral view showed loss of bone density in the thoracic spine with collapse of the D.5 vertebral body. This was approximately the site of the patient's pain.

A clinical diagnosis of a bronchogenic carcinoma with secondary neoplastic deposits in the spine was made and although sputum cytology showed no malignant cells, histology of a subcutaneous nodule, which had appeared in the epigastrium, revealed a deposit of poorly differentiated carcinoma. The most likely source of this seemed to be a bronchus. The history of major fits suggested the presence of cerebral metastases and the pigmentation, the possibility of Addison's disease due to adrenal metastases.

The following investigations were also performed, the results being confirmed by repeated estimations: blood urea $18 \mathrm{mg} / 100 \mathrm{ml}$; serum sodium $109 \mathrm{mEq} / 1$; potassium $3.1 \mathrm{mEq} / 1$; chloride $71 \mathrm{mEq} / 1$; bicarbonate $24 \mathrm{mEq} / 1$; total serum proteins $4.3 \mathrm{~g} / 100 \mathrm{ml}$; albumin 3.4 , glob- 
ulin $1 \cdot 0$, serum calcium $7 \cdot 1 \mathrm{mg} / 100 \mathrm{ml}$; phosphate $4.1 \mathrm{mg} / 100 \mathrm{ml}$; alkaline phosphatase 7.5 KA units $/ 100 \mathrm{ml}$; plasma osmolality 246 $\mathrm{m}$ Osm $/ 1$; urine $752 \mathrm{mOsm} / 1$; urinary sodium excretion $56 \mathrm{mEq} / 24 \mathrm{hr}$.

The low values for blood urea and serum potassium together with the normal blood pressure and the presence of sacral oedema suggesting water retention were incompatible with a diagnosis of Addison's disease and suggested the possibility of a dilutional hyponatraemic syndrome due to inappropriate secretion of antidiuretic hormone, which has been well described in association with bronchogenic carcinoma (Schwartz et al., 1957). This was supported by the high urine osmolality despite a low plasma osmolality.

The following tests of adrenal function were performed: urine 17-hydroxycorticosteroid excretion on three consecutive days $20.6,24.5$ and $15.2 \mathrm{mg} / 24 \mathrm{hr}$; urine 11-hydroxycorticosteroid excretion $1700 \mu \mathrm{g} / 24 \mathrm{hr}$; urine 17-ketosteroid excretion $3.1 \mathrm{mg} / 24 \mathrm{hr}$; plasma 11-hydroxycorticosteroids (Mattingly, 1962) 9.30 a.m.-31.0 $\mu \mathrm{g} /$ $100 \mathrm{ml}, 12$ midnight- $33.0 \mu \mathrm{g} / 100 \mathrm{ml}$. Plasma 11 hydroxycorticosteroids before an i.m. injection of $0.25 \mathrm{mg}$ Synacthen $49.0 \mu \mathrm{g} / 100 \mathrm{ml} ; 30 \mathrm{~min}$ after $0.25 \mathrm{mg}$ Synacthen $61.0 \mu \mathrm{g} / 100 \mathrm{ml}$.

The high value for urine 17-hydroxycorticosteroids and urine 11-hydroxycorticosteroid excretion, together with the high plasma 11hydroxycorticosteroid levels with absence of the normal diurnal variation, revealed that the patient also had Cushing's syndrome. The increase in plasma 11-hydroxycorticosteroids after corticotrophin stimulation (SynacthenCiba) suggested that adrenal hyperplasia was present and it seemed reasonable to assume that the carcinoma was secreting both antidiuretic hormone and adrenocorticotrophic hormone. Unfortunately, the patient's general condition deteriorated a few weeks after admission and he died.

\section{Pathology}

At autopsy, performed $1 \frac{1}{2} \mathrm{hr}$ after death, the body was very wasted and showed slight ankle oedema, a protuberant abdomen and skin pigmentation.

A hard mass of tumour surrounded the left main bronchus and spread in fan-like fashion to the pleura of the mediastinal surface of the left lung for $7 \mathrm{~cm}$ from the hilum. This plaque averaged $5 \mathrm{~mm}$ in thickness and extended to the root of the aorta and the base of the pericardium enveloping the origins of the great vessels. Numerous mediastinal and lower cervical lymph nodes were enlarged by necrotic growth. There was no evidence of a primary bronchial growth or tumour within the lung parenchyma.

The liver was massively enlarged weighing $3000 \mathrm{~g}$ and was largely replaced by nodules of growth. Near the upper border of the body of the pancreas was a hard, spherical nodule $1 \frac{1}{2} \mathrm{~cm}$ across, thought to be a likely primary growth, although other palpable tiny nodules were present in the pancreatic body and tail. Secondary deposits were not found elsewhere and no evidence of any other possible primary source was discovered. The adrenal glands appeared normal externally, weighing $15 \mathrm{~g}$ combined.

Histologically the tumour in all sites proved to be a poorly differentiated carcinoma, similar to an oat-cell bronchial carcinoma. The tumour cells were closely crowded consisting of small, irregular, densely staining nuclei with no visible cytoplasm (Fig. 1). Multiple lung sections showed that some lymphatic permeation of the lungs by growth had occurred but bronchial epithelium looked normal, and the pleural growth invaded

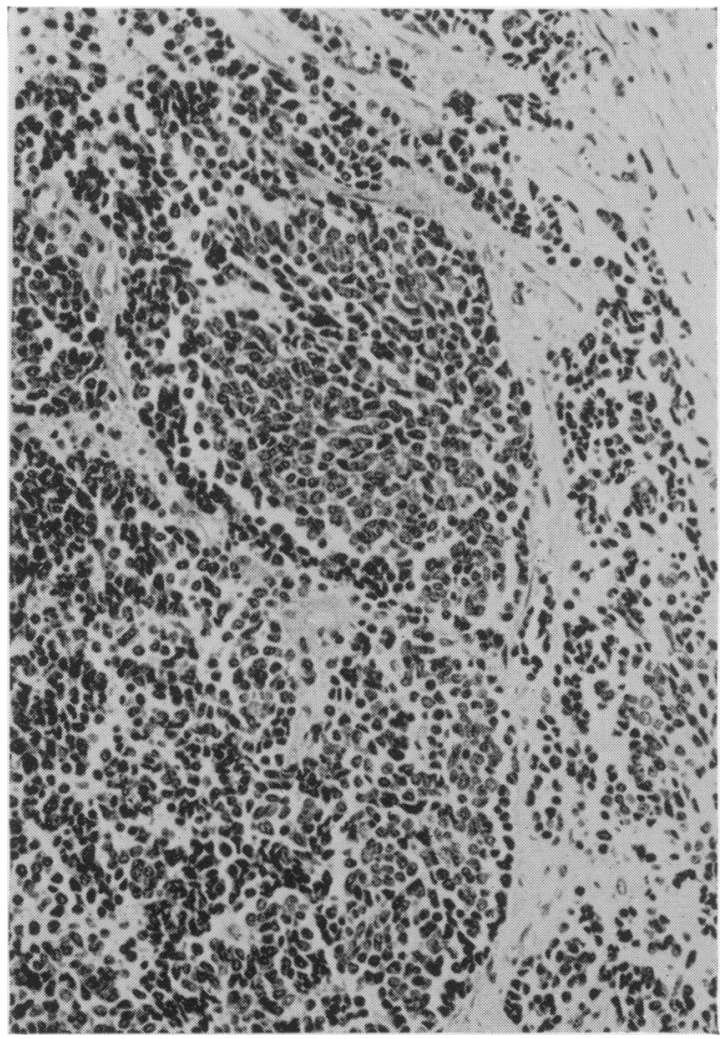

FIG. 1. Anaplastic tumour from site of invasion of lung through mediastinal pleura. Haematoxylin and eosin, $\times 150$. 
the subpleural alveoli only. The pancreatic growth was identical histologically but suggested in outline a secondary deposit, an interpretation supported by the presence of several similar, although much smaller, deposits of growth in the body and tail.

Several nodules of tumour varying from microscopic size to $1 \mathrm{~cm}$ across were present in each adrenal ; the combined adrenal tissue, therefore, weighed considerably less than $15 \mathrm{~g}$, this usually being regarded as the upper limit of normal weight. The adrenals, apart from prominences produced by deposits of growth, were entirely smooth in outline, with no cortical nodularity or 'adenomata' (Fig. 2). The cortex averaged approximately $1.2 \mathrm{~mm}$ thick in paraffin processed sections and was nowhere more than $1.6 \mathrm{~mm}$ thick, measurements which again are well within normal limits. The zona reticularis was, however, proportionately thicker than in normal adrenals occupying on average

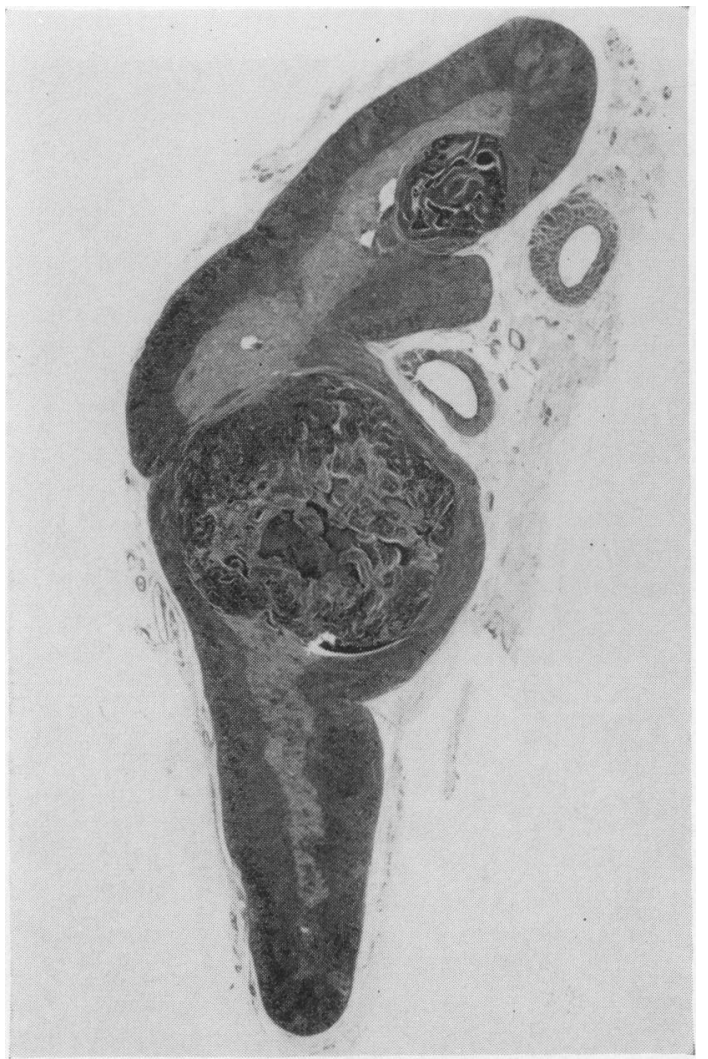

Fig. 2. Section of right suprarenal gland showing two metastatic deposits in a smooth outlined gland of 'normal' size. Haematoxylin and eosin, $\times 3$ approximately. half the cortical width with compact, reticularistype cells extending in a few places to the cortex. Zona glomerulosa cells were limited to small isolated clumps. Zona fasciculata cells were only lipoid containing in the outer layers where occasional clumps of cells were ballooned with lipoid, the inner layers being similar to the compact reticularis cells (Fig 3 ).

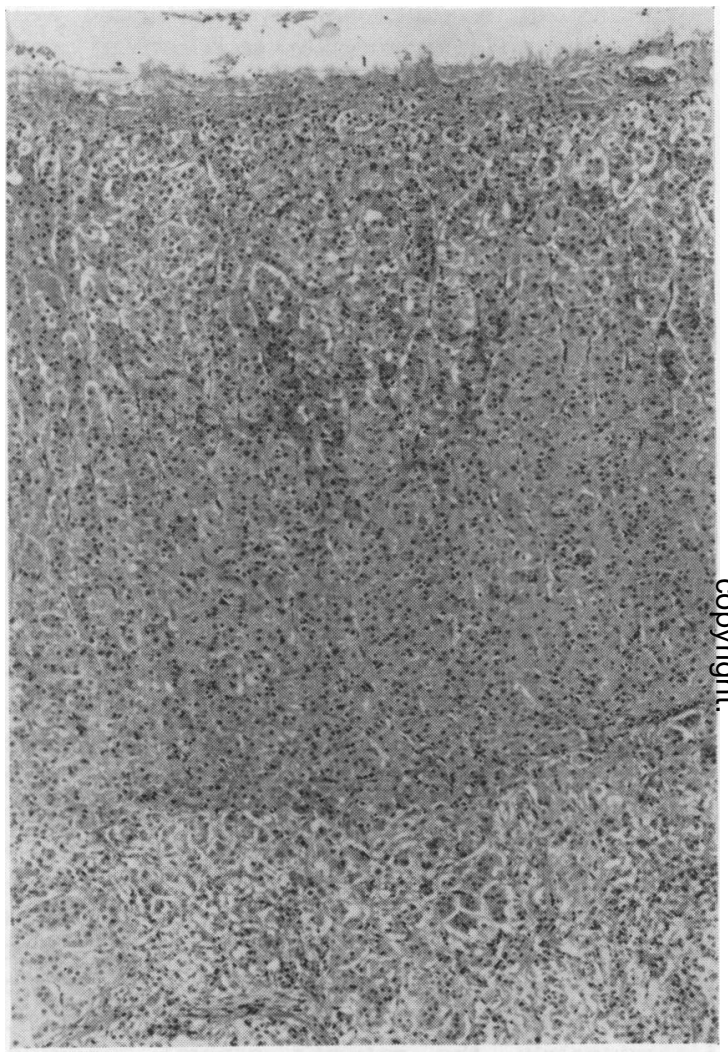

Fig. 3. Detail of suprarenal cortex showing a wide reticularis zone of compact granular cells and slight vacuolation, from lipid content, in fasciculata cells. Haematoxylin and eosin, $\times 50$.

Sections of deltoid, biceps, quadriceps and soleus muscles were taken. In all, there was a considerable degree of non-specific muscular atrophy. In addition, an unusual type of fibre degeneration was present, very prominently in the soleus. This consisted of segmental swelling of muscle fibres with concentration in the swollen fibres of a glycogen-like material. In haematoxylin and eosin preparations, many muscle fibres were markedly swollen, varying from two to five times the normal fibre width (Fig. 4) with 
rounding of the contours of the fibre and with several nuclei within the central portions of the fibre. The swollen sarcoplasm had, in the severely affected fibres, lost all evidence of striation and, in transverse sections, presented a fenestrated appearance with some totally unstained vacuoles lying within a granular eosinophilic background, which stained slightly more palely than the normal surrounding sarcoplasm of the muscle fibres. The bulk of the granular material and much of the vacuolated material stained positively as glycogen and in PAS stained sections very few unstained vacuoles remained. The included nuclei within the cytoplasm were larger and on the whole much more vesiculated than normal sarcolemmal nuclei. No inflammatory infiltration was found in the vicinity of these muscle fibres and no evidence of regenerating muscle fibres or of phagocytosis of totally disintegrated fibres.

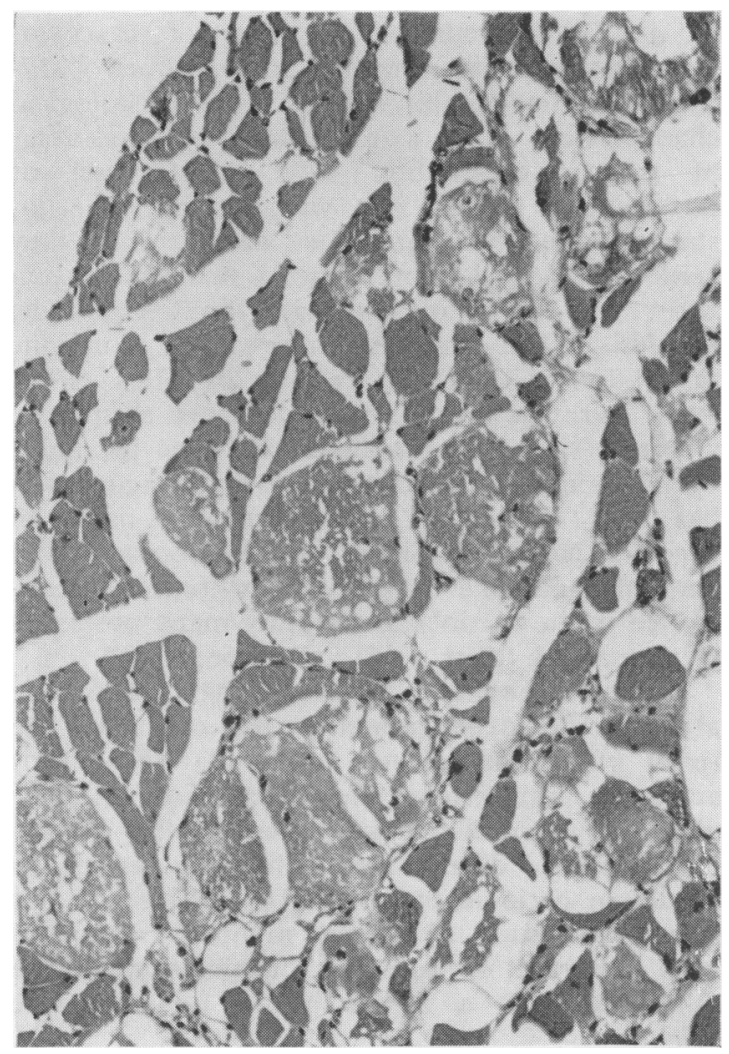

Fig. 4. Swollen, granular and vacuolated muscle fibres in soleus muscle. Haematoxylin and eosin, $\times 210$.

\section{Bioassay results}

Bioassays of the patient's plasma and postmortem tissues for adrenocorticotrophic hormone (Dr B. Davies, Imperial Cancer Research Fund) and antidiuretic hormone (Dr J. Lee, Charing Cross Hospital Medical School) were performed and the results are shown in Table 1. The ACTH bioassay was based on the increase in corticosterone after injection into cortisol-treated rats (Currie \& Davies, 1963) and ADH activity was measured in the water-loaded rat (Lee, Jones \& Barraclough, 1964).

TABLE 1

Antidiuretic and adrenocorticotrophic hormone assay results

\begin{tabular}{lcc}
\hline \multicolumn{1}{c}{ Specimen } & ADH & ACTH \\
\hline Plasma & - & $\begin{array}{c}0.96 \mathrm{mUnits} / 100 \\
\mathrm{ml}^{*}\end{array}$ \\
Pituitary gland & - & 0.349 I.U.† \\
$\begin{array}{c}\text { Liver secondary } \\
\text { deposits }\end{array}$ & $\begin{array}{c}9 \pm 1 \mu \text { Units } / \mathrm{mg} \text { of } \\
\text { acetone-dried } \\
\text { tissue }\end{array}$ & 0.08 I.U./100 g \\
$\begin{array}{c}\text { Tumour from } \\
\text { mediastinum }\end{array}$ & - & 0.126 I.U. $/ 100 \mathrm{~g}$ \\
\hline
\end{tabular}

* Normally 0.8-2.6 mUnits/100 ml.

$\dagger$ Normally about 20 I.U.

$\ddagger$ Normal tissue (lung, liver) contains $<1 \mu$ Units/mg.

Significant quantities of antidiuretic hormone were found in secondary deposits from the liver, but corticotrophin was present only in small amounts in the plasma and in tumour tissue from the liver and mediastinum. The pituitary content of corticotrophin was markedly reduced.

\section{Discussion}

The origin of the tumour in this case was not ascertained with certainty. Histologically and in the pattern of metastatic spread, the tumour was compatible with a bronchogenic neoplasm. It did not have the morphological appearances of either a pancreatic carcinoma or hepatic tumour, which were the other possible sources. An 'oat cell' bronchogenic carcinoma is usually the primary lesion in both antidiuretic and adrenocorticotrophic hormone secreting tumours (Hobbs \& Miller, 1966), but Engel \& Kahana (1963) have emphasized, as in this case, that many corticotrophin-secreting carcinomas are of uncertain origin.

It is interesting that the adrenal glands were of normal size despite the presence of Cushing's syndrome, and the usual finding of adrenal hyperplasia in these cases (Parsons \& Rigby, 1958; Friedman, Marshall-Jones \& Ross, 1966). They did, however, show features said by Ashworth \& Garvey (1958), Cohen, Chapman \& 
Castleman (1959) and Symington \& Jeffries (1960) to be constant in the adrenal glands of cases of spontaneously occurring Cushing's syndrome, whether the glands are hyperplastic by weight or not. All these authors emphasize atrophy of the glomerulosa, and Symington \& Jeffries (1960) particularly stress the prominent reticularis with replacement of the fasciculata cells to some degree by compact granular cells. Cohen et al. (1959) also stress the depletion of lipoid from the hyperfunctioning gland. It is clear, therefore, that the adrenals in this case, although not hyperplastic by weight standards, showed many features of hyperfunctioning adrenal glands. Occasional cases of Cushing's syndrome with normal sized adrenal glands associated with nonendocrine tumours have been reported (O'Riordan et al., 1966). It would be of interest to know whether such 'normal' sized glands showed the histological features previously described.

In this patient, the presence of significant quantitites of antidiuretic material on bioassay of secondary neoplastic deposits in the liver confirms the biochemical evidence that the hyponatraemic syndrome was the result of the tumour secreting an antidiuretic hormone-like substance. It seems most probable that the tumour was also secreting adrenocorticotrophic hormone resulting in adrenal hyperactivity. Strong evidence for this is the low corticotrophin content of the pituitary gland, which suggests pituitary suppression by an ectopic source of corticotrophin. Failure to find increased amounts of corticotrophin in the patient's plasma or tumour is surprising but it is known that the corticotrophin content of plasma on bioassay in patients with Cushing's syndrome is occasionally within normal limits (Nelson, Meakin \& Thorn, 1960). This is presumably due to cyclical activity of the pituitary gland. Such a phenomenon may also have been present in this instance.

The secretion of both corticotrophin and antidiuretic hormone from a single tumour has previously been reported by Liddle et al. (1964). Other cases of adrenal hyperactivity associated with a hyponatraemic syndrome in patients with a bronchogenic carcinoma have been recorded (Rees, Rosalki \& Maclean, 1960 ; Daly, Nelson \& Rose, 1963 ; Branson, Oleesky \& Turnberg, 1966), but bioassays for corticotrophin and antidiuretic hormone were not performed in these instances so one cannot be certain that the tumour was secreting both hormones. It is interesting that, in the latter case (Branson et al., 1966), there was suppression of the tumour by dexamethasone which suggested that it was not autonomously secreting corticotrophin. Antidiuretic hormone is known to have a corticotrophinreleasing action (Landon, James \& Stoker, 1965) and this may account for the presence of adrenal hyperactivity in their case. In the present instance, the possibility of such a mechanism cannot be definitely excluded.

The muscle changes in this case were unlike those which occur in any of the well-recognized myopathic syndromes associated with carcinoma, and the most likely explanation would appear to be the association with hormone secretion that has been demonstrated. In spontaneously occurring Cushing's syndrome, unassociated with carcinoma, considerable muscle weakness is commonly a prominent feature. Müller \& Kugelberg (1959) described five cases of Cushing's syndrome in which muscular weakness was prominent but the histological appearances in the biopsied cases showed only slight changes not similar to those described in this case. Perkoff et al. (1959) reported a series of cases of myopathy associated with administration of 17 hydroxycorticosteroids. Again the histological changes were minor, consisting of scattered areas of muscle vacuolation with proliferation of sarcolemmal nuclei. The vacuoles in some instances contained granular debris and they commented on the similarity of this vacuolation with that seen in patients with familial periodic paralysis. The muscle changes in cortisone myopathy produced in rabbits by Ellis (1953, 1956) were, however, similar to those seen here, although similar appearances could be produced by potassium deficiency. Muscle-fibre vacuolation has been known for many years to occur in periodic paralysis (Singer \& Goodbody, 1901) and glycogen-like material has been demonstrated in the vacuolated fibres by many observers (Poskanzer \& Kerr, 1961; Pearson, 1964).

It seems probable, therefore, that the muscle abnormalities demonstrated in this case were the result of the high levels of circulating steroids acting on intracellular metabolism and, in view of the presence of hypokalaemia, possibly involving a similar disturbance within the muscle as occurs in periodic paralysis. To the best of our knowledge, such a steroid myopathy has not been reported in cases of Cushing's syndrome associated with a carcinoma of non-endocrine origin.

\section{Acknowledgments}

We would like to express our thanks to Dr. G. O. Richardson for permission to publish details of this case and we are indebted to Dr Beryl Davies, The Imperial Cancer Research Fund, and to Dr J. Lee, Charing Cross Hospital Medical School, for respectively performing the 
assays of adrenocorticotrophic hormone and antidiuretic hormone. We would also like to thank Professor A. L. Latner and Dr P. Smith of the Royal Victoria Infirmary, Newcastle upon Tyne, as well as Dr A. C. Smith and Dr R. W. T. Haddon, Newcastle General Hospital, for their help with the investigations and the 'Medlars' Literature Retrieval Service operated by the computing laboratory at the University of Newcastle upon Tyne for a search of published reports.

\section{References}

Ashworth, C.T. \& GARVEY, R.F. (1958) The diffuse adrenal lesion in Cushing's disease. Histological observations on surgically removed adrenals in four cases. Amer. J. Path. 34, 1161.

Branson, J., Oleesky, S. \& TuRnberg, L.A. (1966) a case of carcinoma of the bronchus associated with hormonal abnormalities. Postgrad. med. J. 42, 518.

Brown, W.H. (1928) A case of pluriglandular syndrome'Diabetes of bearded women'. Lancet, ii, 1022.

Cohen, R.B., Chapman, W.B. \& Castleman, B. (1959) Hyperadrenocorticism (Cushing's disease): A study of surgically resected adrenal glands. Amer. J. Path. 35, 537.

Currie, A.R. \& Davies, B.M.A. (1963) Effect of trichloracetic acid on basophils and on corticotrophin content of human pituitary glands. Extraction of low molecular weight corticotrophin. Acta endocr. (Kbh.), 42, 69.

Daly, J.J., Nelson, M.A. \& Rose, D.P. (1963) Hyponatraemia with carcinoma of the bronchus. Postgrad. med.J. 39, 158.

EluIS, J.T. (1953) Studies on the nature and pathogenesis of muscular degeneration in cortisone treated rabbits. Bull. N.Y. Acad. Med. 29, 814.

ELLIS, J.T. (1956) Necrosis and regeneration of skeletal muscles in cortisone treated rabbits. Amer. J. Path. 32, 993.

ENGEL, F.L. \& KaHANA, L. (1963) Cushing's syndrome with malignant corticotrophin producing tumour: Amer.J. Med. 34, 726.

Friedman, M., Marshall-Jones, P. \& Ross, E.J. (1966) Cushing's syndrome: Adrenocortical hyperactivity secondary to neoplasms arising outside the pituitary-adrenal system. Quart. J. Med. N.s. 35, 193.

FusCo, F.D. \& Rosen, S.W. (1966) Gonadotrophin producing carcinomas of the lung. New Engl.J. Med. 275, 507.

DE GenNes, L., BRICAIRe, H. \& LePrat, J. (1962) Les syndromes endocriniens paraneoplasiques. II. Hyperthyroidies et endocrinopathies diverses. Presse méd. 70, 2137.

HARDY, J.D. (1960) Gynaecomastia associated with lung cancer. J. Amer. med. Ass. 173, 1462.

HobBs, C.B. \& Miller, A.L. (1966) Review of endocrine syndromes associated with tumours of non-endocrine origin. J. clin. Path. 19, 119.

LANDON, J., JAMEs, V.H.T. \& STOKER, D.J. (1965) Plasma cortisol response to lysine vasopressin. Lancet, ii, 1156.
LeE, J., Jones, J.J. \& BARRAClough, M.A. (1964) Inappropriate secretion of vasopressin. Lancet, ii, 792.

LidDle, G.W., Givens, J.R., Nicholson, W.E. \& Island, D.P. (1964) The ectopic A.C.T.H. syndrome. Proceedings of The Second International Congress of Endocrinology. Excerpta Medica Foundation.

MATtingly, D. (1962) A simple fluorimetric method for the estimation of free 11 hydroxycorticoids in human plasma. J. clin. Path. 15, 374.

Meador, C.K., Liddle, G.W., Island, D.P., Nicholson, W.E., LuCAS, C.P., NuCKTON, J.G. \& Leutscher, J.A. (1962) Cause of Cushing's syndrome in patients with tumours arising from 'non-endocrine' tissue. J. clin. Endocr. 22, 693.

Müller, R. \& Kugelberg, E. (1959) Myopathy in Cushing's syndrome. J. Neurol. Neurosurg. Psychiat. 22, 134.

Nelson, D.H., Meakin, J.W. \& ThORN, G.W. (1960) A.C.T.H.-producing pituitary tumours following adrenalectomy for Cushing's syndrome. Ann. intern. Med. 52, 560.

O'RioRdan, J.L.H., BlanshaRd, G.P., MOXHAM, A. \& NABARRo, J.D.N. (1966) Corticotrophin-secreting carcinomas. Quart. J. Med. N.s. 35, 137.

Parsons, V. \& Rigby, B. (1958) Cushing's syndrome associated with adenocarcinoma of the ovary. Lancet, $\mathbf{i i}, 992$.

Pearson, C.M. (1964) The periodic paralyses. Differential features and pathological observations in permanent myopathic weakness. Brain, 87, 341.

Perkoff, G.T., Silber, R., Tyler, F.H., Cartwright, E. \& WinTrobe, M.M. (1959) Myopathy due to the administration of therapeutic amounts of 17 hydroxycorticosteroids. Amer. J. Med. 26, 891.

Poskanzer, D.C. \& KeRR, D.N.S. (1961) A third type of periodic paralysis with normokalaemia and favourable response to sodium chloride. Amer. J. Med. 31, 328.

Rees, J.R., Rosalki, S.B. \& Maclean, A.D.W. (1960) Hyponatraemia and impaired renal tubular function with carcinoma of bronchus. Lancet, ii, 1005.

Ross, E.J. (1963) Hyponatraemic syndromes associated with carcinoma of the bronchus. Quart. J. Med. N.s. 32, 297.

SchWartz, W.B., BenNetT, W., Curelop, S. \& BartTer, F.C. (1957) A syndrome of renal sodium loss and hyponatraemia probably resulting from inappropriate secretion of antidiuretic hormone. Amer. J. Med. 23, 529.

Symington, T. \& JefFries, R. (1960) The Human Adrenal Cortex, p. 345. Livingstone, Edinburgh.

Singer, H.D. \& GOODBODY, F.W. (1901) A case of family periodic paralysis with a critical digest of the literature. Brain, 24, 257.

Tashilan, A.H., JR, Levine, L. \& Munson, P.L. (1964) Immunochemical identification of parathyroid hormone in non-parathyroid neoplasms associated with hypercalcaemia. J. exp. Med. 119, 467.

Williams, E.D. \& Azzopardi, J.G. (1960) Tumours of the lung and the carcinoid syndrome. Thorax, 15, 30 . 